\title{
Neuropsychological profile of women with substance-related disorders under treatment in a drug dependence unit
}

\begin{abstract}
This study aims to describe the neuropsychological profile of a clinical sample of drug - dependent women to treatment in a drug dependency. A battery of neuropsychological evaluation was applied to an intentional sample composed of 25 drug-dependent women with subjective complaints of attention and / or memory, who were referred to the area of neuropsychology of the Drug Dependency Unit of the Concello de Vigo CEDRO (Galicia, Spain). The scores related to the cognitive / executive functioning of the sample are indicative of difficulties in visuospatial processing speed $(M=43.79, S D=14.88)$, in the selective attention $(\mathrm{M}=35.91, \mathrm{DT}=25.06)$ and alternating $(\mathrm{M}=30.36, \mathrm{DT}=33.70)$ and in the executive components of inhibition (UPPS-Negative Affect, $\mathrm{M}=1.45$, UPPS-Positive Affect, $M=1.31)$ and TMT flexibility $(M=43.79$, DT = 14.88). Neuropsychological exploration helps identify cognitive difficulties in the cognitive and executive processes of the patients that may affect the interventions performed.
\end{abstract}

Keywords: females, gender, cognitive impairment, executive functions, neuropsychological assessment, dual pathology
Volume 7 Issue I - 2017

\author{
Adolfo Pinon Blanco, 1,3,5 Maria Casanueva \\ Fern ndez, ${ }^{2}$ Tania Torres Rinc n,, 2 Olga \\ Guti rrez Mart nez, ${ }^{2}$ Manuela Fontanillo \\ Fontanillo, ${ }^{2}$ Pilar Dom nguez Gonzalez,' \\ Esperanza Vergara Moragues, ${ }^{3,4}$ Enrique V \\ zquez Justo, ${ }^{3,5}$ Francisco Otero Lamas' \\ 'Assistance Unit for Drug Addiction (UAD) CEDRO,Vigo,Spain \\ 2University Hospital Complex of Vigo, EOXI-CHUVI, Spain \\ ${ }^{3}$ Portucalense Institute of Neuropsychology and Cognitive and \\ Behavioral Neurosciences, University of Porto, Portugal \\ ${ }^{4}$ Faculty of Legal, Social Sciences and Humanities, Department \\ of Psychology, Universidad Internacional de la Rioja (UNIR). \\ Logrono, La Rioja, Spain \\ ${ }^{5}$ Clinics ebam, Poio, Spain
}

\begin{abstract}
Correspondence: Adolfo Pinon Blanco, Assistance Unit for Drug Addiction of the Concello de Vigo CEDRO, Calle Pintor Colmeiro N9, Post code: 362 I I Vigo-Pontevedra, Spain, Email Adolfo.pb@icloud.com
\end{abstract}

Received: November 25, 2016 | Published: January 09, 2017

\section{Introduction}

From a neurobiological perspective, addictive disorders have been defined as a pathology of motivation and decision making. ${ }^{1,2}$ Neuropsychological and neuroimaging studies have been carried out with people who use substances that point to alterations in frontal lobe functioning and associated cognitive functions, where inhibitory control and decision making play a central role. ${ }^{3}$

The use of psychoactive substances has been consistently associated with the presence of alterations in different neuropsychological processes: memory, attention or executive functions. ${ }^{4-8}$

Most studies carried out in the drug-dependent population are mostly or exclusively male, ${ }^{9}$ and few studies have analyzed gender differences, although this aspect is of great relevance for the knowledge of the different disorders, As expressed in the guidelines for the development of future diagnostic classifications.

In the current 2013-2016 Action Plan, the importance of the gender focus for specific attention to drug-dependent women (National Plan on Drugs, 2013a) is highlighted on multiple occasions. These proposals reflect a need already demanded in theoretical and research papers that demonstrate the existence of differences between women and men in terms of drug use and their psychological intervention, often using a traditional non-specific intervention model.

Physiologically it is known that women tend to have a more rapid development of the symptoms associated with dependence, arriving at treatment with less years of consumption and with more severe symptoms and that the neurotoxic effects of Cocaine can cause more CNS damage in men than in women.
The presence of dual pathology and the severity of psychiatric symptomatology make it difficult to treat drug dependence, which indicates the need to simultaneously detect and treat both disorders. ${ }^{10}$ The mortality risk attributable to dual pathology has been found to be significantly higher in women than in men and that women appear to be more vulnerable to presenting psychotic symptoms faster than men.

Taking into account epidemiological data in relation to consumption in Spain, the differences between men and women are becoming smaller, with only women emphasizing the consumption of psychoactive drugs.

There is evidence of high variability in response to methadone treatment among patients indicating that they may have different treatment needs. Men and women in particular are known to differ in susceptibility to addiction and behavior, including the age of first use of opiates, progress to regular use and age of admission treatment. Men and women are also likely to differ in methadone treatment outcomes, although the differences are not clear in the literature. Therefore, current standards of treatment that offer the same clinical treatment of opiate-use disorder for women and men cannot achieve optimal treatment outcomes for both sexes.

Other studies found that women on methadone treatment were less likely than men to use alcohol, but more likely than men to use amphetamines during treatment.

Gender plays an important role in the effects of cocaine, as children prenatally exposed to cocaine as they grow older exhibit more behavioral problems and cognitive deficits (central information processing, motor skills, and management of abstract concepts) than 
non-exposed children. In comparing children and adolescents of both genders with prenatal exposure to cocaine, the children had greater externalising, risky and / or aggressive behaviors than girls.

Taking into account the above, the study that we describe below has as objective to know the neuropsychological profile of a poorly studied user in a drug-dependent population, such as that of women with substance-related disorders to treatment unit of drug dependence.

Our hypothesis is that these patients will present alterations in processing speed, verbal memory, attention and / or executive functions. ${ }^{7,8}$ The results of this work can contribute to identify the difficulties in the cognitive and executive processes of the patients that may be affecting the interventions performed, to better define the individual needs for therapeutic intervention and to orient the neurocognitive rehabilitation objectives more efficiently.

\section{Methods}

\section{Participants}

The sample consisted of 25 women with substance-related disorders under treatment at the "CEDRO" municipality of Vigo drug addiction care unit. Inclusion criteria were to meet the criteria for the diagnosis of substance-related disorders DSM-5 (American Psychiatric Association, 2013), to be treated in CEDRO, to go to the area of neuropsychology of the Care Unit, go through the informed consent procedure And present a period of abstinence of more than 15 days, so it is possible to rule out the presence of withdrawal symptoms or alterations associated with the acute or short-term effects of the substances of consumption.

Those users who were:

1. Over 55 years old,

2. Had intellectual deficits defined as IC $<70$,

3. Had a history of moderate or severe neurological pathology (TBI, stroke, etc.),

4. Were in a psychiatric process Acute,

5. Were not abstinent. The sociodemographic and consumptionrelated characteristics of the sample are described in Table 1.

Table I Sociodemographic and related characteristics of sample consumption

\begin{tabular}{ll}
\hline Age (Mean and Standard Deviation) & $\mathbf{4 2 . 4 0}(\mathbf{8 . 0 7})$ \\
\hline Level of Studies & \\
\hline Basic General Education without finalizing & $20 \%$ \\
Basic General Education & $44 \%$ \\
Compulsory Secondary Education / Vocational Training & $16 \%$ \\
baccalaureate & $16 \%$ \\
Higher education & $4 \%$ \\
\hline Human Immunodeficiency Virus (HIV) & \\
\hline Do not & $68 \%$ \\
Yes & $20 \%$ \\
No analysis last 3 months & $12 \%$ \\
Main Drug & \\
Opiates & $68 \%$ \\
Cocaine & $8 \%$ \\
Other & $24 \%$ \\
Years & $23.48(7.13)$ \\
\hline Treatment Program & \\
\hline Drug Free Treatment Program & $20 \%$ \\
Opiates Derivatives Treatment Program & $68 \%$ \\
Alcohol Interdiction Treatment Program & $4 \%$ \\
Psychostimulant Derivative Treatment Program & $4 \%$ \\
Reception & $4 \%$ \\
\hline
\end{tabular}

Table Continued..

\begin{tabular}{ll}
\hline Age (Mean and Standard Deviation) & $\mathbf{4 2 . 4 0 ~ ( 8 . 0 7 )}$ \\
\hline Abstinence & \\
\hline More than 6 months & $68 \%$ \\
I or 2 consumptions last 6 months & $32 \%$ \\
Methadone dose (mgr.) (Mean, standard deviation) & $33(35.94)$ \\
Dual pathology & $76.90 \% \mathrm{Si} ; 23.10 \%$ \\
\hline Medication & No \\
\hline Psycholeptics & $28 \%$ \\
Psycholeptics + Psychoanalytics & $36 \%$ \\
Psycholeptics + Psychoanalytics + Antiepileptics & $8 \%$ \\
Psycholeptics + Anti-epileptics & $4 \%$ \\
Other combinations of drugs & $8 \%$ \\
Nothing & $16 \%$ \\
\% Patients with prison admission & $20,8 \%$ \\
Average months in prison & $21.54(60.26)$ \\
\hline
\end{tabular}

\section{Measuring instruments}

A data collection questionnaire was developed integrating different variables and a battery of standardized neuropsychological tests that were chosen for their usefulness in the diagnosis of patients with addictions. ${ }^{11}$ Table 2 shows the tests used and the cognitive-executive domains evaluated.

Table 2 Neuropsychological evaluation protocol

\begin{tabular}{ll}
\hline Tests & Evaluated Functions \\
\hline WAIS-III' & \\
\hline Number Key & $\begin{array}{l}\text { Speed of psychomotor processing and visual } \\
\text { motor coordination. }\end{array}$ \\
Arithmetic & $\begin{array}{l}\text { Mental calculation and operational memory. } \\
\text { Digits }\end{array}$ \\
Symbols Search & $\begin{array}{l}\text { Visual perception, psychomotor processing } \\
\text { speed. }\end{array}$ \\
Letters and Numbers & Operational memory. \\
Matrices & Abstract reasoning and fluid intelligence \\
\hline Five Digit Test (FDT) ${ }^{13}$ & \\
\hline Reading & Processing speed reader. \\
Count & Sustained attention and processing speed \\
Choice & reader. \\
Alternation & Selective attention. \\
\hline Stroke Test ${ }^{14}$ & Alternate attention and cognitive inhibition. \\
\hline Part A & \\
Part B & Visuospatial visual search skills. \\
Verbal learning test (TAVEC) & Alternate attention and cognitive flexibility. \\
lowa Gambling Test (IGT) & Verbal memory. \\
Zoo Test (BADS) & Emotional component of decision making. \\
UPPS-P25 & Planning ability. \\
\hline
\end{tabular}

Wechsler Scale ${ }^{12}$ for the Measurement of Adult and Adolescent Intelligence (WAIS III): It is a battery of appreciation of the general intelligence that consists of 14 tests grouped into two scales: verbal and manipulative. In this study we used the subtests required to calculate the processing speed index (number key and symbol search) and the working memory index (letters-numbers, digits and arithmetic) in addition to the subtest of matrices. The Working Memory Index (IMT) is related to numerical ability and sequential processing. It involves responding to oral stimuli that relate to the handling of numbers or letters in a progressive and sequential process and requires good attention and short-term memory. The Process Velocity Index (IVP) is related to the speed of response when solving a set of nonverbal problems. It implies speed of thought and motor speed. The matrix subtest evaluates abstract reasoning, perceptual organization, and visual information processing. The WAIS indices scores are distributed with an average of 100 points and a standard deviation 
of 15 , while the scoring scores of the subtests have an average of 10 and a standard deviation of 3 points. The reliability coefficients (two halves) of the scale range from 0.77 to $0.96 .{ }^{12}$

Test of the 5 Digits ${ }^{13}$ : It is an instrument that allows a very brief and simple evaluation of the speed of cognitive processing, the ability to focus and reorient attention and the ability to cope with interference. It is based on the well-known Stroop effect, but instead of using words and colors as stimuli, figures or digits are used, allowing a greater variety of tests and their use with people of lower cultural level, even people who do not know the language or They do not know how to read. It consists of four parts of independent application, in which are presented series of 50 boxes containing 1 to 5 digits (parts 1,3 and 4) or stars (part 2) each, organized in patterns similar to those of the figures Dominoes or playing cards. In part 1 (reading) the individual is asked to read as quickly as possible, in rows, the digit that contains each box. In part 2 (count) you are asked to count, also in rows and as fast as you can, how many stars each box contains. In part 3 (choice) you are asked to count the number of digits in each box, causing an interference effect, since the boxes have groups of digits that do not correspond to their arithmetic value (eg, in A box with five doses, the correct answer would be five instead of two). This section is equivalent to the interference condition of the Stroop test Finally, in part 4 (alternation) you are asked to count, as you did in part 3 , or read, as you did in part 1, depending on whether the box in the box is normal (count , $80 \%$ of the stimuli), or double thickness (read, $20 \%$ of the stimuli). Parts 1 and 2 (reading and counting) of the test are basic measures of attention and processing speed. In contrast, parts 3 and 4 (interference and change) are sensitive to the operation of executive processes of selective attention and suppression of automatic responses. The score on each part of the test is the time taken to complete the corresponding task, which is subsequently converted to a percentile score. The normative data are used for Spanish drugdependent population that includes the test.

Trail Making Test ${ }^{14}$ : The TMT, known as a trail test or stroke test, consists of two parts: part A is a measure of viso-motor and processing capacity and speed ${ }^{15}$; Part B evaluates cognitive flexibility. ${ }^{16}$ In part A, the subject must connect numbered circles and randomly distributed on a sheet, in the correct numerical order $(1,2,3$, 4, etc.). In Part B, in addition to circles with numbers, circles are added with letters. The subject is asked to connect numbers and letters in an alternating and ascending sequence (1-A-2-B-3-C, etc.) in the shortest possible time. Scoring is the time taken to complete this task. The normative data in Spanish are used for young adults. ${ }^{17}$

Verbal Learning Test Spain-Complutense ${ }^{18}$ : The TAVEC is a Spanish adaptation of the California Verbal Learning Test ${ }^{19}$ and consists of several parts. Specifically, 2 lists (A and B) are composed of 16 words that can be grouped into four semantic categories (spices, tools, fruits and clothing) to evaluate learning, inference, recall and recognition. The interpretation of the test follows a line that surpasses the "multiware" model and is integrated into theories of modularity of mind and allows to determine the "normality" of the subject (comparing with a similar sample in age, sex and educational level), Describe the mode of operation of your memory system, determine the form and reason for its deviation (if any), indications about suspected dementia, etc. The test allows to assess the range of immediate memory, provides a learning curve, reveals inclinations towards backward and pre-active interference patterns, evaluates the existing confabulation in memory tasks, and measures the retention present after an interference activity. Of the different measures offered by the test, the present study uses the total immediate recall index and the recognition index. The normative data are used for Spanish population that includes the test.
Iowa Gambling Task $\left(\right.$ IGT, $\left.{ }^{20}\right)$ : IGT is a neuropsychological test to simulate real-life decision making that is widely used in the investigation of cognition and emotion. Patients with frontal orbital cortex dysfunction make risky choices in this task. The IGT is a computerized test that evaluates decision making with an emotional component and consists of four sets of cards: A, B, C, D. The goal of the task is to accumulate as much money and lose as little as possible. Decks A and B are risky (with high profits and high losses); However, decks $\mathrm{C}$ and $\mathrm{D}$, are conservative (generate lower profits but lower losses). The electronic version of the test in Spanish was used and the instructions proposed in the test use manual were used. The reinforcement and punishment program is structured in such a way that the difference between reinforcements and punishments in disadvantaged decks is net loss. In contrast, this difference between rewards and punishments in advantageous decks results in a net gain. In order to score the performance of the participant in the task, the total number of cards chosen from the disadvantageous decks (A and B) is summed and the result of this sum is subtracted from the total number of cards selected from the advantageous decks (C and D). The result of this algebraic sum gives a net score for the total of the test considered as adaptive if it is less than or equal to zero. ${ }^{21}$

Test of the BADS Zoo Map ${ }^{22}$ : The BADS executive function battery is used for the evaluation of patients with disejecutive syndrome, a frontal lobe syndrome. Evaluate problem solving, attention, organizational skills over extended periods of time and daily life skills to prioritize competition demands. The Zoo map test is a BADS subtest that measures planning ability (a specific executive function). The test consists of two parts (with and without instructions). In each one of them the participant must visit different points in a map of a zoo (the house of the monkeys, the gallery of reptiles ...), following an ordered sequence under certain restrictions of passage, marking its route between points with pencils of different colors. For each part of the test the number of hits (a visited place in the position to be visited) is subtracted in the sequence (there are four correct sequences), the number of errors made in the proposed sequence (deviations, the shaded areas ...). These are the direct scores of the first and second part of the test that depending on their value and the time to complete the sequence is translated to a profile with a value between 0 and 4 . The higher the profile number, the better Performed the test. The Zoo Map has shown high validity and reliability (inter-rater reliability $\kappa>0.96)^{22}$ and several studies have shown that BADS has higher ecological validity indexes than other classic tests of executive functions. ${ }^{23,24}$

Impulsive behavioral scale (UPPS-P, ${ }^{25}$ ): It is a scale of 59 elements designed to measure five components of impulsive behavior:

1. Negative urgency. It evaluates the tendency of an individual to yield to strong impulses, especially when accompanied by negative emotions such as depression, anxiety or anger;

2. Lack of perseverance. Evaluates an individual's ability to persist in performing tasks or duties despite boredom and / or fatigue;

3. Lack of premeditation. It evaluates the individual's ability to think about the possible consequences of his or her behavior before acting;

4. Search for sensations. Evaluates the measures of preference of an individual of excitation and stimulation;

5. Positive urgency. It evaluates an individual's tendency to yield to impulses in conditions of high positive affect. The Spanish adaptation of the scale ${ }^{26}$ was used. Each item of the UPPS 
is graded on a 4-point scale from very strongly to strongly disagreeing. The score on the five subscales and the total score are expressed in standard deviations. The scale has good psychometric properties and can be considered a promising instrument for its use in research contexts and especially for its brevity in clinical contexts. ${ }^{26}$

\section{Process}

Participants were recruited by consecutive sampling of patients from the "CEDRO" Drug Dependence Unit who presented subjective complaints of attention and / or memory. They were given a battery of neuropsychological tests (see Table 2) according to the application rules and the correction criteria specific to each manual. The evaluations were carried out between the years 2013-2016. All tests were applied in the neuropsychology area of CEDRO in similar conditions. Two 60-minute evaluation sessions were conducted. Sociodemographic and consumption variables were collected from the center's database. Participation in the study was voluntary. The users signed an informed consent in accordance with the Organic Law 1/1999 of December 13 on the protection of personal data

\section{Results}

Mean WAIS-III scores on working memory indices (IMT, $\mathrm{M}=$ 99.14, DT $=12.02$ ) and processing speed (IVP, $\mathrm{M}=94.87, \mathrm{DT}=$ 10.31) correspond to normative performance. More specifically, the means obtained in the subtests of Digits $(\mathrm{M}=11.30$, DT $=2.60)$, Search for Symbols $(M=9.13$, DT $=2.45)$, Matrices $(M=8.76$, DT $=2.58)$, Letters and Numbers $=10.17, \mathrm{DT}=2.98)$ and Arithmetic $(\mathrm{M}$ $=8.26, \mathrm{DT}=2.52$ ) correspond to an average yield. Obtaining an IQ rated as a mean $(\mathrm{M}=97.42, \mathrm{SD}=13.99)$.

The mean scores obtained in the Five Digit Test (FDT) indicate a mean performance in reading $(\mathrm{M}=52.18, \mathrm{SD}=34.67)$ and counting $(\mathrm{M}=53.00, \mathrm{SD}=38.41)$, as well as, Choice $(\mathrm{M}=35.91, \mathrm{DT}=25.06)$ and alternation $(\mathrm{M}=30.36, \mathrm{DT}=33.70)$.

The mean scores in part A of TMT $(\mathrm{M}=43.79, \mathrm{SD}=14.88)$ and in part $\mathrm{B}(\mathrm{M}=89.43, \mathrm{SD}=29.05)$ correspond to a Severe Impairment $($ Percentile $=25)$.

Regarding TAVEC, both the scores obtained in the total immediate recall index $(\mathrm{M}=-0.75, \mathrm{DT}=1.06)$ and the recognition scores $(\mathrm{M}$ $=-0.20, \mathrm{DT}=1.17)$ are within the mean range of $+/-2$ Deviations Typical and therefore, they are considered normative.

The mean scores obtained in the IGT correspond to a score qualified as adaptive $(\mathrm{M}=5.70, \quad \mathrm{DT}=18.94)$. In the zoo map test, the following mean scores were obtained (Part 1, $\mathrm{M}=2.67, \mathrm{DT}=2.99$, Part 2, $\mathrm{M}=8.00, \mathrm{DT}=.00$; Profile Score, $\mathrm{M}=$ $2.11, \mathrm{DT}=.90)$

Regarding the UPPS impulsivity scale, the lack of premeditation subscales $(\mathrm{M}=0.54, \mathrm{DT}=1.11)$, lack of perseverance $(\mathrm{M}=0.51$, DT $=1.02)$ and sensation search $(\mathrm{M}=0.18, \mathrm{DT}=0.89)$ show Criteria of normality. The subscales of negative affect $(\mathrm{M}=1.45$, DT $=0.87)$, positive affect $(\mathrm{M}=1.31 \mathrm{DT}=1.35)$ and total impulsivity $(\mathrm{M}=1.11$, $\mathrm{DT}=0.71)$ correspond to moderate impulsivity.

By way of summary, Table 3 shows the mean scores and standard deviations obtained in all tests of the neuropsychological battery administered.

\section{Discussion}

The objective of this study is to describe the neuropsychological profile of a clinical sample of drug-dependent women undergoing treatment in a drug dependence unit. The hypothesis was that these patients present alterations in processing speed, verbal memory, attention and / or executive functions.

Table 3 Mean scores (and typical deviations) of the tests performed

\begin{tabular}{ll}
\hline Tests & \\
\hline WAIS-III & $8.92(1.76)$ \\
\hline Number Key & $8.26(2.52)$ \\
Arithmetic & $11.30(2.60)$ \\
Digits & $9.13(2.45)$ \\
Search Symbols & $10.17(2.98)$ \\
Letters and Numbers & $8.76(2.58)$ \\
Matrices & $99.14(12.02)$ \\
Work Memory Index (IMT) & $94.87(10.31)$ \\
Processing Speed Index (IVP) & $97.42(13.99)$ \\
Total Intellectual Ratio (CIT) & \\
\hline Five Digit Test (FDT) & $52.18(34.67)$ \\
\hline Reading & $53.00(38.41)$ \\
Count & $35.91(25.06)$ \\
Choice & $30.36(33.70)$ \\
Alternation & \\
\hline Trail Making Test (TMT) & $43.79(14.88)$ \\
\hline Part A & $89.43(29.05)$ \\
Part B & \\
\hline Verbal Learning Test (TAVEC) & $-0.75(1.06)$ \\
\hline Immediate total recall & $-0.20(1.17)$ \\
Recognition & $5,70(18.94)$ \\
lowa Gambling Test (IGT) & \\
\hline Zoo Test (BADS) & $2.67(2.99)$ \\
\hline Part I & $8.00(.00)$ \\
Part 2 & $2.11(.90)$ \\
Profile & \\
\hline UPPS-P & $1.45(0.87)$ \\
\hline Negative Affection & $0.54(1.11)$ \\
Lack of premeditation & $0.51(1.02)$ \\
Lack of perseverance & $0.18(0.89)$ \\
Sensation Search & $1.31(1.35)$ \\
Positive Affection & $1.11(0.71)$ \\
Total score & \\
\hline & \\
\hline & \\
\hline
\end{tabular}

In the specific tests of processing speed, an average performance in tasks of psychomotor processing speed (WAIS-III) and reader (FDT-Reading), and inferior performance in visuospatial processing (TMT-A) is observed. The finding of apparently contradictory results in different tests used to measure the same function is relatively frequent in the addiction literature. ${ }^{27}$

Several authors ${ }^{9,28}$ have described clinical models of care based on experimental research and clinical observation of patients with brain damage at different recovery levels. Considering the clinical model of care $^{28}$ that divides attention into different sub processes, the results of the present study suggest adequate arousal and focused attention (WAIS-III digits) and sustained (FDT-Count) Presenting difficulties in selective (FDT-Election) and alternating (FDT-Alternation and TMT-B) tasks. In particular, the deficits in attentional subprocesses are reflected in the difficulties they present in maintaining sustained attention when the required tasks are boring or monotonous, when they have to select the relevant information to be addressed and the irrelevant must ignore, or when they have to be flexible and adapt their behavior to novel or changing situations. In this sense, numerous studies coincide to find that addicts present attention deficit, in comparison with their respective control groups. ${ }^{29-32}$

The scores obtained in the verbal memory specific test (TAVEC) are indicative of normative functioning. Other studies have also found no alterations using classical measures of verbal memory 
based on word lists..$^{31,33,34}$ These data should not be interpreted as indicative of the absence of dysfunctions in the memory subsystems in this population, since a broader mnesic assessment, ${ }^{35}$ including the strategic components of memory. ${ }^{36}$

In relation to executive functioning, several authors have used factor analysis to identify the components underlying the construct executive functions. ${ }^{37,38}$ One of the most recognizable factorial models $^{39,40}$ probably classifies the executive components into four independent but related components, Change, inhibition and decision making). In our study we have chosen an approach based on the main executive components isolated in factorial studies and patients with focal lesions ${ }^{26}$ that structure the executive functioning in the components of actualization, inhibition, flexibility, planning / Multitasking and decision making.

The neuropsychological profile of the studied sample is characterized by alterations in the executive components of flexibility (TMT-B and FDT-Alternation) and inhibition (FDT-Election, UPPS Negative Affect, Positive and Total Impulsivity). These results are consistent with previous research that has shown a significant influence of prolonged drug use on the functioning of different components of executive function. ${ }^{8}$

The findings of this study should be considered, however, preliminary and should be interpreted with caution. Future studies should take into account several limitations that complicate the interpretation of these results. In this sense, it is possible that the results obtained in the process of neuropsychological assessment are affected by the effects exerted on the cognitive functions of the psychiatric pathology that suffer from a high percentage of the patients studied and the pharmacological treatment that they take regularly to treat those pathologies, Although it seems evident that they present important alterations in the executive functions. It is also necessary to take into account the limitations inherent to studies in the drug-dependent population, such as heterogeneous samples (policonsumidores, consumption pattern), low level of cognitive reserve $^{6}$ Causal relationship between neuropsychological alterations and prolonged substance use. Future studies should employ larger samples, a randomized control group, a greater number of women, EEG-based neuromarkers, functional neuroimaging techniques, and functional connectivity analysis.

Finally, the data obtained contribute to the description of the neuropsychological profile of women to treatment in a drug dependence unit, describing the deficient and conserved areas of each patient, facilitating the differential diagnosis and individualization of the treatment. ${ }^{41-75}$

\section{Acknowledgments}

None.

\section{Conflicts of interest}

None.

\section{Funding}

None.

\section{References}

1. Kalivas PW, Volkow ND. The neural basis of addiction: a pathology of motivation and choice. Am J Psychiatry. 2005;162(8):1403-1413.

2. Volkow ND, Koob GF, McLellan AT. Neurobiologic advances from the brain disease model of addiction. The New England Journal of Medicine. 2016;374:363-371.
3. Yücel M, Lubman DI. Neurocognitive and neuroimaging evidence of behavioral dysregulation in human drug addiction: implications for diagnosis, treatment and prevention. Drug Alcohol Rev. 2007;26(1):33-39.

4. Coullaut-Valera R, Arbaiza-Diaz del Rio I, Arrue-Ruilo R, et al. Cognitive impairment associated with the use of different psychoactive substances. Spanish Proceedings of Psychiatry. 2011;39:168-173.

5. Garavan H, Stout JC. Neurocognitive insights into substance abuse. Trends in Cognitive Sciences. 2005;9(4):195-201.

6. Vázquez-Justo E, Piñón-Blanco A, Vergara-Moragues E, et al. Cognitive reserve during neuropsychological performance in HIV intravenous drug users. Applied Neuropsychology. Adult. 2014;21(4):288-296.

7. Vázquez-Justo E, Vergara-Moragues E, Piñón-Blanco A, et al. Neuropsychological functioning in methadone maintenance patients with HIV. Revista Latinoamericana de Psicología. 2016;48(3):147-158.

8. Verdejo-García A, Orozco Giménez C, Meersmans Sánchez-Jofré M, et al. Impact of the severity of drug use on different components of the executive function. Journal of Neurology. 2004;38(12):1109-1116.

9. Kalechstein A, van Gorp WG. Neuropsychology and Substance Use. State of the art and Future directions. New York and London: Taylor and Francis. 2007.

10. Cohen RA. The neuropsychology of attention. New York: Plenum Press, USA. 1993.

11. Sieira-Valiño J, Iglesias-Fungueiriño M, Sánchez Pérez M, Vázquez Justo E, Guillén Gestoso C, Neuropsychological battery for cognitive rehabilitation in drug dependence. Cadiz: Interdisciplinary Training Institute, University of Cadiz. 2011.

12. Wechsler D. Wechsler Intelligence Scale for Adults III. Madrid: TEA. 2001

13. Sedó M. Test of the Five Digits. Madrid: T.E.A. Ediciones. 2007.

14. Reitan RM, Wolfson D. The Halstead-Reitan Neuropsychological Test Battery. Theory and Clinical Interpretation. Tucson, Arizona: Neuropsychology Press. 1993. p.93-129.

15. Tirapu-Ustárroz J, Luna-Lario P. Neuropsychology of executive functions. In: Tirapu-Ustárroz, et al. (Eds.), Manual of neuropsychology. Barcelona: Viguera Publishers, Spain. 2008. p.219-249.

16. Kortte KB, Horner MD, Windham WK. The trail making test, part B: Cognitive flexibility or ability to maintain set? Appl Neuropsychol. 2002;9(2):106-109.

17. Tamayo F, Casals-Coll M, Sánchez-Benavides G, et al. Spanish normative studies in the young adult population (Young NEURONORMA Project): standards for verbal span tests, visuospatial span, Letter-Number Sequencing, Trail Making Test and Symbol Digit Modalities Test. Neurologia. 2012; 27(6):319-329.

18. Benedet MJ, Alejandre MA. Verbal Apprenticeship Test SpainComplutense (TA $\neg$ VEC). Madrid: TEA. 1998.

19. Delis DC, Kramer JH, Kaplan E, et al. California Verbal Learning Test: Adult Version. San Antonio: The Psychological Corporation. 1987.

20. Bechara A, Damasio AR, Damasio H, et al. Insensitivity to future consequences following damage to human prefrontal cortex. Cognition. 1984;50(1-3): 7-15.

21. Verdejo-García A, Bechara A, Recknor EC, et al. Decision-making and the iowa gambling task: ecological validity in individuals with substance dependence. Psychologica Belgica. 2006;46(1-2): 55-78.

22. Wilson BA, Alderman N, Burgess PW, et al. Behavioral Assessment of Dyssexual Syndrome. St. Edmunds, UK: Thamer Valley Test Company, Harcout Assessment. 1996. 
23. Espinosa A, Alegret M, Boada M, et al. Ecological assessment of executive functions in mild cognitive impairment and mild Alzheimer's disease. J Int Neuropsychol Soc. 2009;15(5):751-757.

24. Verdejo-García A, Pérez-García M. Ecological assessment of executive functions in substance dependent individuals. Drug Alcohol Depend. 2007;90(1):48-55.

25. Lynam DR, Smith GT, Whiteside SP, et al. The UPPS-P: Assessing five personality pathways to impulsive behavior (Technical Report). West Lafayette: Purdue University, USA. 2006.

26. Verdejo-García A, Lozano O, Moya M, et al. Psychometric properties of a Spanish version of the UPPS-P impulsive behavior scale: reliability, validity and association with trait and cognitive impulsivity. $J$ Pers Assess. 2010;92(1):70-77.

27. Lorea I, Fernández-Montalvo J, Tirapu-Ustárroz J, et al Neuropsychological performance in cocaine addiction: a critical review. Rev Neurol. 2010;51(7):412-426.

28. Sohlberg MM, Mateer CA. Introduction to Cognitive Rehabilitation. New York: Guilford, USA. 1989.

29. Goldstein RZ, Leskovjan AC, Hoff AL, et al. Severity of neuropsychological impairment in cocaine and alcohol addiction: association with metabolism in the prefrontal cortex. Neuropsychology. 2004; 42(11):1447-1458.

30. Pace-Schott EF, Morgan PT, Malison RT, et al. Cocaine users differ from normals on cognitive tasks which show poor performance during drug abstinence. Am J Drug Alcohol Abuse. 2008; 34(1):109-121.

31. Ruiz JM, Pedrero E, Llanero M, et al. Neuropsychological profile in cocaine addiction: considerations about the social environment close to addicts and the predictive value of cognitive status in therapeutic success. Addictions. 2009;21:119-132.

32. Woicik PA, Moeller SJ, Alia-Klein N, et al. The neuropsychology of cocaine addiction: recent cocaine use masks impairment. Neuropsychopharmacology. 2009;34(5):1112-1122.

33. Hoff AL, Riordan H, Morris L, et al. Effects of crack cocaine on neurocognitive function. Psychiatry Res. 1996;60(2-3): 167-176.

34. van Gorp WG, Wilkins JN, Hinkin CH, et al. Declarative and procedural memory functioning in abstinent cocaine abusers. Arch Gen Psychiatry. 1999;56(1):85-89.

35. Squire LR, Knowlton BJ. The temporal medial lobe, the hippocampus, and the memory systems of the brain. In: M Gazzaniga (Edr.), The New Cognitive Neurosciences. Cambridge, Massachusetts: MIT Press, USA. 2000. p.765-779.

36. Tirapu-Ustárroz J, Muñoz-Céspedes JM. Memory and executive functions. Journal of Neurology . 2005;41:475-484.

37. Boone KB, Pontón MO, Gorsuch RL, et al. Factor analysis of four measures of prefrontal lobe functioning. Arch Clin Neuropsychol. 1998;13(7):585-595.

38. Busch RM, McBride A, Curtiss G, et al. The components of executive functioning in traumatic brain injury. $J$ Clin Exp Neuropsychol. 2005;27(8):1022-1032.

39. Miyake A, Friedman NP, Emerson MJ, et al. The unity and diversity of executive functions and their contributions to complex frontal lobe tasks: A latent variable analysis. Cogn Psychol. 2000; 41(1):49-100.

40. Miyake A, Friedman NP, Rettinger DA, et al. How are visuospatial working memory, executive functioning, and spatial abilities related? A latent-variable analysis. J Exp Psychol Gen. 2001;130(4):621-640.

41. Aharonovich E, Edward N, Hasin D. Cognitive impairment, retention and abstinence among cocaine abusers in cognitive-behavioral treatment. Drug Alcohol Depend. 2003;71(2):207-211.
42. Aharonovich E, Hasin DS, Brooks AC, et al. Cognitive deficits predict low treatment retention in cocaine dependent patients. Drug Alcohol Depend. 2006;81(3):313-322.

43. Baddeley A, Emslie H, Kolodny J, et al. Random generation and the executive control of working memory. $Q J$ Exp Psychol A. 1998;51(4):819-852.

44. Baldo JV, Shimamura AP. Letter and category fluency in patients with frontal lobe lesions. Neuropsychology. 1998;12(2):259-267.

45. Baldo JV, Shimamura AP, Delis DC, et al. Verbal and design fluency in patients with frontal lobe lesions. $J$ Int Neuropsychol Soc. 2001;7(5):586-596.

46. Benton A, Hamsher KS. Multilingual aphasia examination. Iowa: University of Iowa, USA. 1989.

47. Braver TS, Barch DM, Kelley WM, et al. Direct comparison of prefrontal cortex regions engaged by working and long-term memory tasks. Neuroimage. 2001;14(1 Pt 1):48-59.

48. Buchert R, Thomasius R, Wilke F, et al. A Voxel-Based PET Investigation of the Long-Term Effects of Ecstasy Consumption on Brain Serotonin Transporters. Am J Psychiatry. 2004;161(7):1181-1189.

49. Butfield E, Zangwill O. Reeducation in aphasia: a review of 70 cases. $J$ Neurol Neurosurg Psychiatry. 1946;9(2):75-79.

50. Chang L, Ernst T, Strickland T, et al. Gender effects on persistent cerebral metabolite changes in the frontal lobes of abstinent cocaine users. American Journal of Psychiatry. 1999;156(5):716-722.

51. Christensen H, Korten AE, Jorm AF, et al. Education and decline in cognitive performance: Compensatory but not protective. Int J Geriatr Psychiatry. 1997;12(3):323-330.

52. Della Sala S, Gray C, Spinnler H, et al. Frontal lobe functioning in man: the riddle revisited. Arch Clin Neuropsychol. 1998;13(8):663-682.

53. Fernández-Serrano MJ, Pérez-García M, Verdejo-García A. What are the specific vs. Generalized effects of drugs on neuropsychological performance? Neurosci Biobehav Rev. 2011;35(3):377-406.

54. Garcia-Torres A, Vergara-Moragues E, Vergara-Moragues A. GALA Project. A pilot study of neuropsychological evaluation and intervention in GERASA Home. In: A Piñón Blanco, Therapeutic Games: El Trisquel, Vigo: Concello de Vigo. 2014. p.295-312.

55. Gillen RW, Kranzler HR, Bauer LO, et al. Neuropsychologic findings in cocaine-dependent outpatients. Prog Neuropsychopharmacol Biol Psychiatry. 1998;22(7):1061-1076.

56. Levy B, Monzani BA, Stephansky MR, et al. Neurocognitive impairment in patients with co-occurring bipolar disorder and alcohol dependence upon discharge from inpatient care. Psychiatry Res. 2008;161(1):28-35.

57. Lezak MD. Neuropsychological assessment. New York: Oxford University Press, USA. 2004.

58. Lezak MD, Howieson DB, Loring DW. Neuropsychological assessment. New York: Oxford University Press, USA. 2004

59. Lin WC, Chou KH, Chen HL, et al. Structural deficits in the emotion circuit and cerebellum are associated with depression, anxiety and cognitive dysfunction in methadone maintenance patients: a voxelbased morphometric study. Psychiatry Res. 2012;201(2):89-97.

60. Marshall DF, Walker SJ, Ryan KA, et al. Greater executive and visual memory dysfunction in comorbid bipolar disorder and substance use disorder. Psychiatry Res. 2012;200(2-3):252-257.

61. Moscovitch, M. Confabulation. In: Schacter, et al. (Eds.), Memory Distortion: How Minds, Brains, and Societies Reconstruct the Past. Cambridge, MA: Harvard University Press, USA. 1995. p.226-254.

62. Peña-Casanova J. Integrated Program of Neuropsychological Exploration. Manual. Test Barcelona. Barcelona: Masson, Spain. 1990. 
63. Piñón Blanco A. The trisquel. A game as a tool for cognitive stimulation for treatment with drug addicts. Cadiz: Interdisciplinary Training Institute, University of Cadiz, Spain. 2009.

64. Piñón Blanco A. Memodado. Cadiz: Interdisciplinary Training Institute, University of Cadiz, Spain. 2010.

65. Piñón Blanco A. Therapeutic games: El Trisquel. Vigo: Concello de Vigo. 2014

66. Piñón-Blanco A, Otero-Lamas F, Vázquez-Justo E, et al. Holistic neuropsychological rehabilitation program for people with neuropsychological deficits associated with drug use (PHRN.DROG). Cadiz: Interdisciplinary Training Institute, University of Cadiz, Spain. 2013.

67. Rodríguez D. Afectación neuropsicológica temprana asociada a la infección por VIH and drogodependientes. Thesis Doctoral. Facultad de Psicologia, Universidad de Santiago de Compostela (Spain). 2000.

68. Romero-Martínez A, Moya-Albiol L. Neuropsychological deficits associated with the relationship between cocaine abuse and violence: facilitating neural mechanisms. Addictions. 2015;27:64-74.

69. Rosselli M, Ardila A. The impact of culture and education on non-verbal neuropsychological measurements: A critical review. Brain Cogn. 2003;52(3):326-333.
70. Schrimsher GW, Parker JD. Changes in cognitive function during substance use disorder treatment. Journal of Psychopathological and Behavioral Assessment. 2008;30(2):146-153.

71. Spanish Society of Drug Addiction. Consensus Document for the Approach of Addictions from the Neurosciences. 2009.

72. Tarter RE, Kirisci L, Mezzich A, et al. Neurobehavioral disinhibition in childhood predicts early age at onset of substance use disorder American Journal of Psychiatry.2003;160(6):1078-1085.

73. Tirapu J, Landa, N, Lorea I. Brain and addiction. A comprehensive guide. Navarra: Government of Navarre. Health Department. 2004.

74. Verdejo-García A, Bechara A. Neuropsychology and drug addiction: evaluation, clinical impact and applications for rehabilitation. In: Pérez García (Edr.), Manual of clinical neuropsychology, Madrid: Pyramid. 2009. p.179-208.

75. Verdejo-García A, Bechara A. Neuropsychology of executive functions. Psicothema. 2010;22(2):227-235. 